\title{
MODELLING CHEMICAL-LOOPING ASSISTED BY OXYGEN \\ UNCOUPLING (CLAOU): ASSESSMENT OF NATURAL GAS \\ COMBUSTION WITH CALCIUM MANGANITE AS OXYGEN CARRIER
}

\author{
Alberto Abad*, Pilar Gayán, Luis F. de Diego, Francisco García-Labiano, \\ Juan Adánez
}

Instituto de Carboquímica (ICB-CSIC), Miguel Luesma Castán 4, 50018, Zaragoza, Spain

$$
\begin{aligned}
& \text { * Corresponding author: } \\
& \text { e-mail: abad@icb.csic.es }
\end{aligned}
$$

Mailing address: Instituto de Carboquímica, Miguel Luesma Castán 4, 50018, Zaragoza, Spain

Phone: 976733977 
Submitted, accepted and published by

Proceedings of the Combustion Institute 37 (2019) 4361-4369

\begin{abstract}
Chemical-Looping Combustion (CLC) is a promising technology for performing $\mathrm{CO}_{2}$ capture in combustion processes at low cost and with lower energy consumption. Fuel conversion modelling assists in optimizing and predicting the performance of the CLC process under different operating conditions. For this work, the combustion of natural gas was modelled using a $\mathrm{CaMnO}_{3}$-type perovskite as oxygen-carrier and taking into consideration the processes of fluid dynamics and reaction kinetics involved in fuel conversion. The CLC model was validated against experimental results obtained from the $120 \mathrm{~kW}_{\text {th }}$ CLC unit at the Vienna University of Technology (TUV). Good agreement between experimental and model predictions of fuel conversion was found when the temperature, pressure drop, solids circulation rate and fuel flow were varied. Model predictions showed that oxygen transfer by means of the gas-solid reaction of the fuel with the oxygen-carrier was relevant throughout the entire fuel-reactor. However, complete combustion could be only achieved under operating conditions where the process of Chemical-Looping assisted by Oxygen Uncoupling (CLaOU) became dominant, i.e. a relevant fraction of the fuel was burnt with molecular oxygen $\left(\mathrm{O}_{2}\right)$ released by the oxygen-carrier. This phenomenon was improved by the design configuration of the $120 \mathrm{~kW}_{\text {th }}$ CLC unit at TUV, in which oxidized particles are recirculated to the upper part of the fuel-reactor. Thus, the validated model identified the conditions at which complete combustion can be achieved, demonstrating that it is a powerful tool for the simulation and optimization of the CLC process with the $\mathrm{CaMnO}_{3}$-type material.
\end{abstract}

Keywords: $\mathrm{CO}_{2}$ capture; Chemical-Looping Combustion; methane; modelling; perovskite. 
Submitted, accepted and published by

Proceedings of the Combustion Institute 37 (2019) 4361-4369

\section{Nomenclature}

$d_{p} \quad$ particle diameter $(\mathrm{m})$

e relative error $(\%)$

$f_{s} \quad$ solids fraction (-)

$F_{\text {exc }}$ excess flow generated in the emulsion with respect to minimum fluidization $(\mathrm{mol} / \mathrm{s})$

$F_{j, i} \quad$ molar flow of gas $i$ in the $j$ phase $(\mathrm{mol} / \mathrm{s})$

$m_{F R} \quad$ specific mass of oxygen-carrier in the fuel-reactor $(\mathrm{kg} / \mathrm{MW})$

$\dot{m}_{O C} \quad$ solids circulation flow rate $(\mathrm{kg} / \mathrm{s})$

$Q_{i} \quad$ volumetric flow of gas $i\left(\mathrm{~m}^{3} / \mathrm{h}\right.$ S.T.P. $)$

$R_{O C, \text { ou }}$ oxygen transport capacity for the oxygen uncoupling reaction (kg oxygen per kg solids)

$R_{O C, t} \quad$ total oxygen transport capacity (kg oxygen per kg solids)

$T_{F R} \quad$ fuel-reactor temperature $(\mathrm{K})$

$u_{g} \quad$ gas velocity $(\mathrm{m} / \mathrm{s})$

$X_{\mathrm{CH}_{4}}$ methane conversion (-)

$X_{O C, k} \quad$ oxygen-carrier conversion for reaction $k(-)$

$z \quad$ position in the axial direction $(\mathrm{m})$

Greek symbols

$\Delta P_{F R}$ pressure drop in the fuel-reactor $(\mathrm{Pa})$

$\phi \quad$ oxygen-carrier-to-fuel ratio (-)

$\eta_{\text {comb }}$ combustion efficiency (-)

$\rho_{O C} \quad$ solids density $\left(\mathrm{kg} / \mathrm{m}^{3}\right)$

Subscripts

$j \quad$ phase ( $d b$ : dense bed; $c l$ : cluster; tr: transport; dil: dilute; $b$ : bubbles; $e$ : emulsion)

in inlet

ILS internal loop seal 
Submitted, accepted and published by

Proceedings of the Combustion Institute 37 (2019) 4361-4369

out outlet

USL upper loop seal

Acronyms

CLaOU Chemical-Looping assisted by Oxygen Uncoupling

CLC Chemical-Looping Combustion

DCFB Dual Circulating Fluidised Bed

fWGS forward Water Gas Shift

TUV Vienna University of Technology 
Submitted, accepted and published by

Proceedings of the Combustion Institute 37 (2019) 4361-4369

\section{Introduction}

Chemical-Looping Combustion (CLC) is a novel combustion technology that involves the use of an oxygen-carrier to transfer oxygen from air to the fuel, avoiding the direct contact between the two [1]. The main advantage of CLC is that it allows combustion with inherent $\mathrm{CO}_{2}$ separation at low cost and with low energy consumption [2]. CLC uses a separate air-reactor and fuel-reactor; see Fig. 1. Interconnected fluidized beds appear to be the preferred configuration for fuel and airreactors [1,3]. A solid oxygen-carrier, normally a metal oxide $\left(\mathrm{M}_{\mathrm{x}} \mathrm{O}_{\mathrm{y}}\right)$, transports the oxygen between the reactors. Inside the fuel-reactor, the oxygen-carrier is reduced as the fuel is oxidized. Inside the air-reactor, the oxygen-carrier is returned to its original state through oxidization with air. Consequently, direct contact is prevented between the fuel and air, and combustion products are not diluted in $\mathrm{N}_{2}$; however, the net chemical reaction and combustion enthalpy are the same as those found in conventional combustor with air.

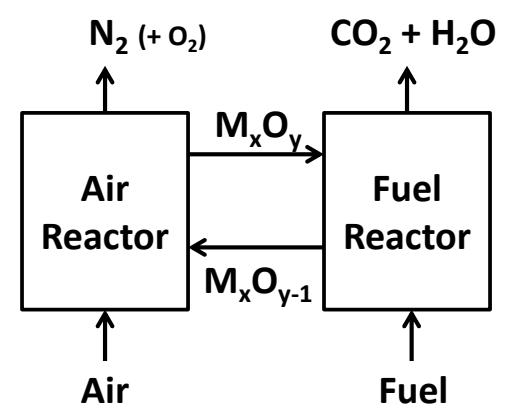

Fig. 1. Reactor scheme of the CLC process.

Among the oxygen-carriers used, $\mathrm{CaMnO}_{3}$-type oxygen-carriers have been found to be promising materials owing to their oxygen uncoupling capability, or ability to spontaneously release gasphase $\mathrm{O}_{2}$ in the fuel-reactor, and the long life-time of their particles [4-7]. The oxygen uncoupling process is particularly beneficial for solid fuels [8], but it can also be favourable for gaseous fuels since the presence of gas phase oxygen could facilitate the full combustion of fuel in a gas-gas reaction without need for the perfect mixing of gases and solids. 
Submitted, accepted and published by

Proceedings of the Combustion Institute 37 (2019) 4361-4369

The next challenge is to scale up CLC technology to $10 \mathrm{MW}_{\text {th }}$ [9]. Considering the experience gained in CLC plants, some questions are still pending to be solved due to the results does not identify the operating conditions mainly affecting to the $\mathrm{CH}_{4}$ conversion, and therefore the optimization of both the design of the CLC unit and operating conditions cannot be determined. In this context, the availability of theoretical model validated against experimental results is a powerful tool to realize the safe scale-up of CLC. However, few models have been validated against experimental results in continuously operated CLC units [1], and no models have been developed with perovskite-type materials including oxygen uncoupling capability.

In this work, a detailed fluid dynamics and kinetics model was developed for a fuel-reactor in order to obtain a simulation tool for the combustion of methane with a $\mathrm{CaMnO}_{3}$-type oxygencarrier. The CLC model was validated against experimental results obtained from the $120 \mathrm{~kW}_{\text {th }}$ Dual Circulating Fluidised Bed (DCFB) at Vienna University of Technology (TUV) burning natural gas and using $\mathrm{CaMg}_{0.1} \mathrm{Mn}_{0.9} \mathrm{O}_{3-\delta}$ as oxygen-carrier. Some insights into the relevance of the oxygen uncoupling process to the complete combustion of natural gas are analysed and discussed.

\section{CLC model}

The theoretical model for the fuel-reactor considered the main processes affecting the reaction of methane with the oxygen-carrier, such as reactor fluid dynamics, the reactivity of the oxygencarrier and the reaction mechanism. The model considered the dimensions and operating conditions for the DCFB at TUV [4]; see Fig. 2.

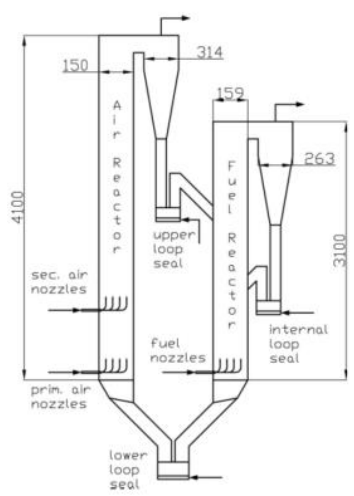

\begin{tabular}{|c|c|}
\hline & Fuel reactor \\
\hline Height, $H_{r}(\mathrm{~m})$ & 3.0 \\
\hline Diameter, $d_{\text {react }}(\mathrm{m})$ & 0.159 \\
\hline Height for inlet gas from loop seals ${ }^{(1)}(\mathrm{m})$ & 0.35 \\
\hline Height for inlet solids from loop seals ${ }^{(2)}(\mathrm{m})$ & 2.0 \\
\hline
\end{tabular}

Fig. 2. Schematic diagram of the DCFB at TUV [4]. 
Submitted, accepted and published by

Proceedings of the Combustion Institute 37 (2019) 4361-4369

\subsection{Fluid dynamics model}

The fuel-reactor was considered to be a fluidized bed working at a high-velocity regime, and it was divided into two vertical zones with respect to axial concentration and back-mixing of solids $[10,11]:$

1. A bottom or dense bed with a high and roughly constant concentration of solids. Solids in the emulsion were in perfect mixing. In the dense bed, the gas is distributed between the emulsion phase and the visible bubbles and the throughflow phases, with gas exchange by diffusion among them. Gas in the emulsion is always considered at minimum fluidization conditions, and any excess of gas either in the gas fed or generated during the $\mathrm{CH}_{4}$ conversion $\left(F_{\text {exc }}\right)$, must move from the emulsion to the visible bubbles and the throughflow.

2. A freeboard or dilute region above the dense bed, where there was a pronounced decay in solids concentration with height. The dilute region is composed of a cluster phase and a transport (dispersed) phase. The cluster phase was in perfect mixing with solids in the dense bed, but the transport phase was characterized by a core/annulus structure with a net flow up of solids in plug flow through the core.

The equations on which the fluid dynamic model is based are compiled in Fig. 3. Most of them are empiric equations compiled by others [12], but no specific fitting of parameters has been done for the CLC model of the $120 \mathrm{~kW}_{\text {th }}$ unit.

\subsection{Mass balances inside the fuel-reactor}

Mass balances were developed for each phase in the dense bed and the dilute region. The pathway for methane conversion with the oxygen-carrier in the fuel-reactor is described by the reaction system in Table 1 . Following reaction (R1), $\mathrm{H}_{2} \mathrm{O}$ was considered a primary product of the methane combustion and $\mathrm{CO}$ was considered an intermediate product [13]. The presence of small amounts of $\mathrm{CO}$ together unconverted $\mathrm{CH}_{4}$ justifies the mechanism [4]. Then, $\mathrm{CO}$ could be converted to $\mathrm{CO}_{2}$ by the forward water-gas shift (fWGS) reaction or by reaction with the oxygen-carrier; see reactions (R2) and (R3). Subsequently, the $\mathrm{H}_{2}$ produced in the fWGS reaction would be able to 
Submitted, accepted and published by

Proceedings of the Combustion Institute 37 (2019) 4361-4369

react with the oxygen-carrier; see reaction (R4). Also, gaseous oxygen was evolved from the solid oxygen-carrier -reaction (R5)- which would be able to react with gaseous fuels $\left(\mathrm{CH}_{4}, \mathrm{CO}\right.$ or $\left.\mathrm{H}_{2}\right)$ in a homogeneous reaction; see reactions (R6)-(R8).

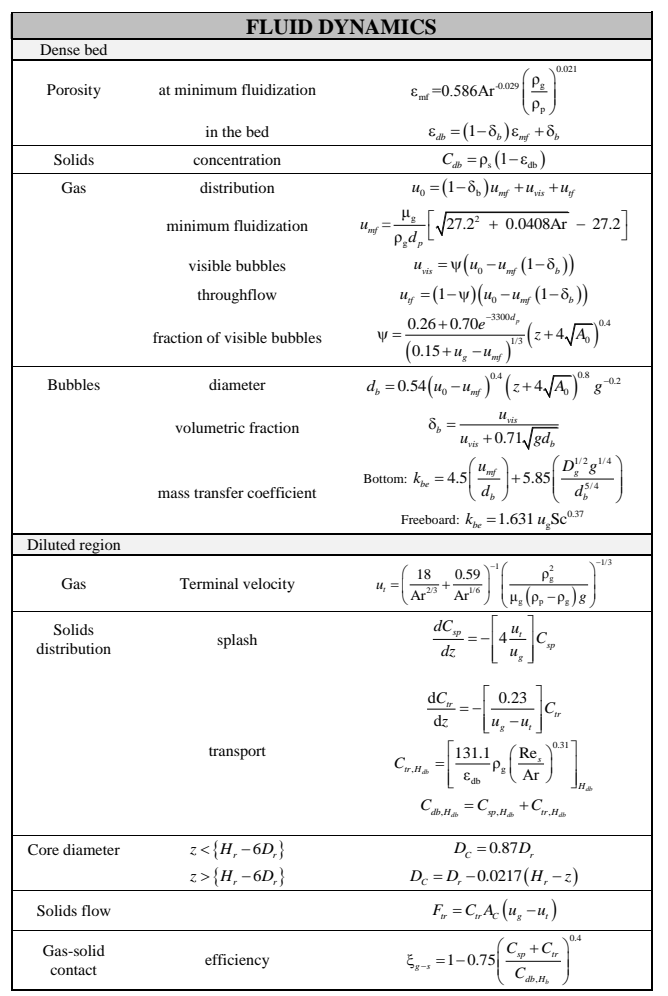

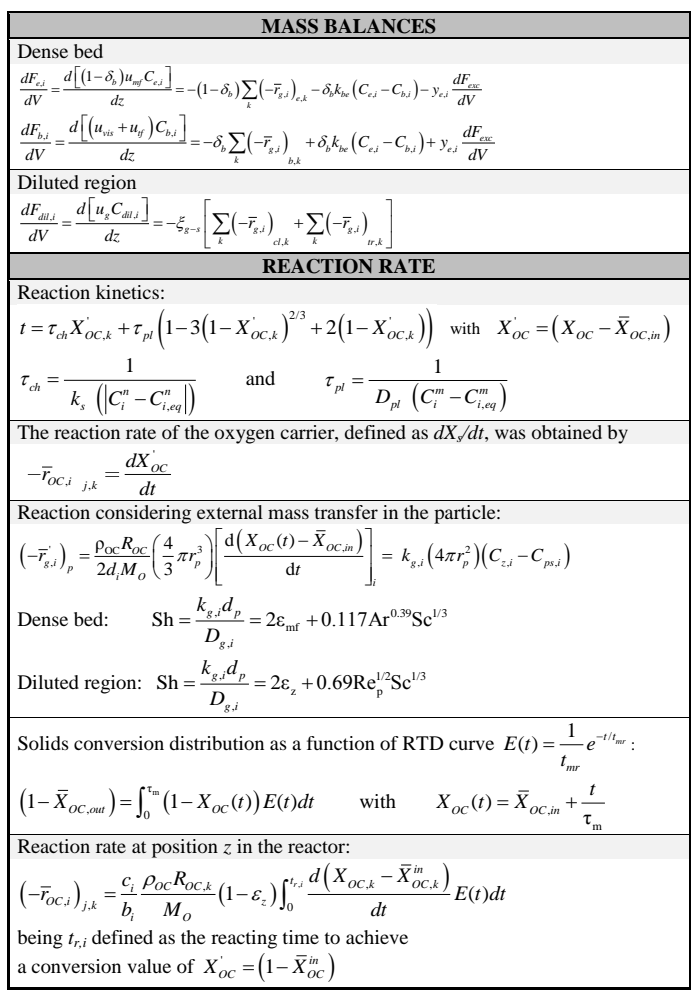

Fig. 3. Compilation of equations used in the fluid dynamic and mass balances sections of the model $[11,14]$. 
Submitted, accepted and published by

Proceedings of the Combustion Institute 37 (2019) 4361-4369

Table 1. Reaction scheme of methane with the $\mathrm{CaMg}_{0.1} \mathrm{Mn}_{0.9} \mathrm{O}_{3-\delta}$ material.

\begin{tabular}{|l|l|}
\hline $3 \mathrm{M}_{\mathrm{x}} \mathrm{O}_{\mathrm{y}}(\mathrm{s})+\mathrm{CH}_{4}(\mathrm{~g}) \rightarrow 3 \mathrm{M}_{\mathrm{x}} \mathrm{O}_{\mathrm{y}-1}(\mathrm{~s})+\mathrm{CO}(\mathrm{g})+2 \mathrm{H}_{2} \mathrm{O}(\mathrm{g})$ & $(\mathrm{R} 1)$ \\
\hline $\mathrm{CO}(\mathrm{g})+\mathrm{H}_{2} \mathrm{O}(\mathrm{g}) \rightarrow \mathrm{CO}_{2}(\mathrm{~g})+\mathrm{H}_{2}(\mathrm{~g})$ & $(\mathrm{R} 2)$ \\
\hline $\mathrm{M}_{\mathrm{x}} \mathrm{O}_{\mathrm{y}}(\mathrm{s})+\mathrm{CO}(\mathrm{g}) \rightarrow \mathrm{M}_{\mathrm{x}} \mathrm{O}_{\mathrm{y}-1}(\mathrm{~s})+\mathrm{CO}_{2}(\mathrm{~g})$ & $(\mathrm{R} 3)$ \\
\hline $\mathrm{M}_{\mathrm{x}} \mathrm{O}_{\mathrm{y}}(\mathrm{s})+\mathrm{H}_{2}(\mathrm{~g}) \rightarrow \mathrm{M}_{\mathrm{x}} \mathrm{O}_{\mathrm{y}-1}(\mathrm{~s})+\mathrm{H}_{2} \mathrm{O}(\mathrm{g})$ & $(\mathrm{R} 5)$ \\
\hline $2 \mathrm{M}_{\mathrm{x}} \mathrm{O}_{\mathrm{y}}(\mathrm{s}) \rightarrow 2 \mathrm{M}_{\mathrm{x}} \mathrm{O}_{\mathrm{y}-1}(\mathrm{~s})+\mathrm{O}_{2}(\mathrm{~g})$ & $(\mathrm{R} 6)$ \\
\hline $\mathrm{CH}_{4}(\mathrm{~g})+1.5 \mathrm{O}_{2}(\mathrm{~g}) \rightarrow \mathrm{CO}(\mathrm{g})+2 \mathrm{H}_{2} \mathrm{O}(\mathrm{g})$ & $(\mathrm{R} 7)$ \\
\hline $\mathrm{CO}(\mathrm{g})+0.5 \mathrm{O}_{2}(\mathrm{~g}) \rightarrow \mathrm{CO}_{2}(\mathrm{~g})$ & $(\mathrm{R} 8)$ \\
\hline $\mathrm{H}_{2}(\mathrm{~g})+0.5 \mathrm{O}_{2}(\mathrm{~g}) \rightarrow \mathrm{H}_{2} \mathrm{O}(\mathrm{g})$ & \\
\hline
\end{tabular}


Submitted, accepted and published by

Proceedings of the Combustion Institute 37 (2019) 4361-4369

The variation of the flow of every compound, i.e. $\mathrm{CH}_{4}, \mathrm{CO}, \mathrm{H}_{2}, \mathrm{CO}_{2}, \mathrm{H}_{2} \mathrm{O}$ and $\mathrm{O}_{2}$, in each phase described in the fluid dynamics model is given by the differential equations compiled in Fig. 3 . They include the main processes by which a compound can appear or disappear in a phase: chemical reaction, diffusion, and bulk gas transfer, $F_{\text {exc }}$, due to volumetric expansion during methane conversion. The reaction rate was obtained considering the residence time distribution of the solids. In addition, the oxygen transport capacity and conversion of oxygen-carrier were defined considering the possible mass loss of a reaction $k$. Two oxygen transport capacity parameters were differentiated: (1) the total oxygen transport capacity of the solids with a gas fuel, $R_{O C, t}$, about $10 \mathrm{wt} \%$; and (2) the oxygen transport capacity in oxygen uncoupling, $R_{O C, \text { ou }}$, about 1 $\mathrm{wt} \%$. More details regarding the kinetics and thermodynamics of the $\mathrm{CaMg}_{0.1} \mathrm{Mn}_{0.9} \mathrm{O}_{3-\delta}$ material are found elsewhere [14]. Kinetics parameters for fresh $\mathrm{CaMg}_{0.1} \mathrm{Mn}_{0.9} \mathrm{O}_{3-\delta}$ particles were considered as no variation in reactivity was observed in a CLC unit [15].

Kinetics of the fWGS reaction -reaction (R2)- and homogeneous combustion of fuel gases $\left(\mathrm{CH}_{4}\right.$, $\mathrm{H}_{2}$ and $\mathrm{CO}$ ) -reactions (R6-R8)- were taken from [16] and [17]. It was assumed that $\mathrm{H}_{2}$ combustion would only occur in the emulsion phase in the bottom bed [18].

\section{Model results}

The theoretical model was developed in Fortan Code ${ }^{\circledR}$ and solved following the method described by Abad et al. [10]. The main outputs of the model were the axial profiles of gas and solids. From these outputs, the performance of the DFBC system was assessed by calculating methane conversion and combustion efficiency.

$$
\begin{aligned}
X_{\mathrm{CH}_{4}} & =\frac{F_{i n, C H_{4}}-F_{\text {out }, \mathrm{CH}_{4}}}{F_{\text {in }, \mathrm{CH}}} \\
\eta_{\text {comb }} & =1-\frac{\left(4 F_{\mathrm{CH}_{4}}+F_{C O}+F_{\mathrm{H}_{2}}\right)_{\text {out }}}{\left(4 F_{\mathrm{CH}_{4}}\right)_{\text {in }}}
\end{aligned}
$$


Submitted, accepted and published by

Proceedings of the Combustion Institute 37 (2019) 4361-4369

The relevance of possible amounts of $\mathrm{CO}$ or $\mathrm{H}_{2}$ was also evaluated with these parameters. Consequently, the amounts of $\mathrm{CO}$ and $\mathrm{H}_{2}$ at the fuel-reactor outlet were lower the closer $\eta_{\text {comb }}$ was to $X_{\mathrm{CH}_{4}}$.

The theoretical model focused on the processes occurring in the fuel-reactor of the DCFB at TUV when methane was burnt with $\mathrm{CaMn}_{0.9} \mathrm{Mg}_{0.1} \mathrm{O}_{3-\delta}$ particles as oxygen-carrier $\left(\rho_{\mathrm{OC}}=3330 \mathrm{~kg} / \mathrm{m}^{3}\right.$, $\left.d_{p}=130 \mu \mathrm{m}\right)$. Table 2 shows the 29 experimental conditions in the fuel-reactor, in addition to the methane conversion obtained, which was used for model validation. Steady state conditions are used to evaluate the experiments [4]. The reactor temperature, pressure drop, solids circulation rate and fuel power were varied in these experiments. The solids circulation rate was calculated by measuring the difference in the oxygen-carrier conversion entering and leaving the air-reactor, following the procedure described elsewhere [19]. 
Submitted, accepted and published by

Proceedings of the Combustion Institute 37 (2019) 4361-4369

Table 2. Operating conditions in experiments during methane combustion with $\mathrm{CaMn}_{0.9} \mathrm{Mg}_{0.1} \mathrm{O}_{3-\delta}$ oxygen-carrier in the DCFB at TUV [4].

\begin{tabular}{|c|c|c|c|c|c|c|c|c|c|c|c|c|}
\hline Test & $T_{F R}(\stackrel{\circ}{ } \mathrm{C})$ & $\Delta P_{F R}(\mathrm{kPa})$ & $Q_{\mathrm{CH}_{4}}\left(\mathrm{Nm}^{3} / \mathrm{h}\right)$ & $Q_{\mathrm{H}_{2} \mathrm{O}, \mathrm{LL} S}\left(\mathrm{Nm}^{3} / \mathrm{h}\right)$ & $Q_{\mathrm{H}_{2} \mathrm{O}, \text { ULS }}\left(\mathrm{Nm}^{3} / \mathrm{h}\right)$ & $R_{O C, t}(\%)$ & $R_{O C, \text { ou }}(\%)$ & $\dot{m}_{O C}(\mathrm{~kg} / \mathrm{h})$ & $X_{O C, \text { in }}(\%)$ & $\phi$ & $m_{F R}(\mathrm{~kg} / \mathrm{MW})$ & $X_{C H 4}(\%)$ \\
\hline 1 & 949 & 7.5 & 11.2 & 2.5 & 3.7 & 9.8 & 1.2 & 4138 & 3.6 & 12.8 & 138 & 82.7 \\
\hline 2 & 948 & 7.4 & 11 & 2.5 & 3.7 & 9.8 & 1.2 & 4063 & 3.7 & 12.8 & 139 & 82.2 \\
\hline 3 & 951 & 7.5 & 11.7 & 2.5 & 3.7 & 9.8 & 1.2 & 4675 & 2.9 & 13.8 & 133 & 84.2 \\
\hline 4 & 951 & 6.6 & 8 & 2.5 & 3.7 & 9.8 & 1.3 & 3588 & 3.4 & 15.7 & 172 & 88 \\
\hline 5 & 946 & 8 & 7.6 & 2.5 & 3.7 & 9.9 & 1.3 & 4506 & 3.2 & 20.8 & 220 & 92.1 \\
\hline 6 & 950 & 7.8 & 7.9 & 2.5 & 3.7 & 9.9 & 1.3 & 5474 & 3.1 & 24.2 & 204 & 92.7 \\
\hline 7 & 949 & 6.6 & 7.5 & 2.5 & 3.7 & 9.8 & 1.2 & 2746 & 3.6 & 12.7 & 180 & 85.4 \\
\hline 8 & 898 & 6.9 & 7.9 & 2.5 & 3.7 & 10.1 & 1.5 & 3726 & 3.4 & 16.9 & 182 & 74.8 \\
\hline 9 & 950 & 7.6 & 7.8 & 2.5 & 3.7 & 9.8 & 1.3 & 3844 & 3.7 & 17.2 & 203 & 89.2 \\
\hline 10 & 950 & 8.8 & 7.9 & 2.5 & 3.7 & 9.8 & 1.3 & 4731 & 3.5 & 20.9 & 230 & 91.1 \\
\hline 11 & 947 & 9.6 & 7.7 & 2.5 & 3.7 & 9.8 & 1.3 & 4550 & 3 & 20.5 & 257 & 92.1 \\
\hline 12 & 950 & 9.7 & 6 & 2.5 & 5 & 9.9 & 1.3 & 4983 & 3.1 & 29.2 & 337 & 99.1 \\
\hline 13 & 948 & 9.6 & 6 & 2.5 & 3.7 & 9.9 & 1.3 & 5471 & 3.4 & 31.8 & 333 & 97.9 \\
\hline 14 & 948 & 9.8 & 5.4 & 2.5 & 5 & 9.9 & 1.3 & 5910 & 3.2 & 38 & 369 & 99.7 \\
\hline 15 & 947 & 10.5 & 7.9 & 2.5 & 3.7 & 9.8 & 1.3 & 5671 & 3.2 & 25 & 275 & 91.4 \\
\hline 16 & 946 & 19.3 & 6.8 & 2.5 & 3.7 & 9.9 & 1.3 & 6317 & 3.2 & 32.6 & 589 & 95 \\
\hline 17 & 948 & 10.3 & 6 & 2.5 & 3.7 & 9.9 & 1.3 & 5825 & 2.9 & 34 & 355 & 97.9 \\
\hline 18 & 947 & 31.4 & 6 & 2.5 & 5 & 9.9 & 1.3 & 6058 & 3.1 & 35.6 & 1104 & 98.6 \\
\hline 19 & 924 & 7.9 & 5.9 & 2.5 & 3.7 & 10 & 1.4 & 3960 & 3.3 & 23.8 & 279 & 87.8 \\
\hline 20 & 923 & 7.1 & 5.9 & 2.5 & 3.7 & 10 & 1.4 & 3032 & 3.6 & 18.2 & 251 & 81.1 \\
\hline 21 & 963 & 7.1 & 5.9 & 2.5 & 3.7 & 9.8 & 1.2 & 2982 & 3.8 & 17.6 & 248 & 90.1 \\
\hline 22 & 962 & 7.6 & 5.8 & 2.5 & 3.7 & 9.8 & 1.3 & 4471 & 3.5 & 26.7 & 272 & 94.6 \\
\hline 23 & 922 & 9.1 & 5.7 & 2.5 & 3.7 & 10 & 1.4 & 3211 & 3.3 & 20 & 332 & 85.3 \\
\hline 24 & 922 & 10 & 5.9 & 2.5 & 3.7 & 10 & 1.4 & 4872 & 3.1 & 29.1 & 352 & 90.2 \\
\hline 25 & 948 & 11.9 & 6.1 & 2.5 & 3.7 & 9.9 & 1.3 & 5522 & 3.4 & 31.8 & 404 & 92.7 \\
\hline 26 & 950 & 8.1 & 8.4 & 2.5 & 3.7 & 9.9 & 1.3 & 5570 & 3.6 & 23.3 & 203 & 83 \\
\hline 27 & 948 & 10.2 & 6.1 & 2.5 & 3.7 & 9.9 & 1.3 & 4926 & 2.8 & 28.4 & 349 & 93.4 \\
\hline 28 & 950 & 10.3 & 5.5 & 2.5 & 4.9 & 9.9 & 1.3 & 5143 & 3.2 & 33.1 & 392 & 97.1 \\
\hline 29 & 949 & 10.1 & 5.6 & 2.5 & 3.7 & 9.9 & 1.3 & 5527 & 3.1 & 34.3 & 374 & 95.9 \\
\hline
\end{tabular}


Submitted, accepted and published by

Proceedings of the Combustion Institute 37 (2019) 4361-4369

The solids circulation flow rate affected the variation of solids conversion in the reactor [20]. The conversion of solids for the global mass balance to the system was calculated with $R_{O C, t}$. However, $R_{O C, \text { ou }}$ was used to obtain the conversion of solids for the oxygen uncoupling reaction. The values of both $R_{O C, t}$ and $R_{O C, \text { ou }}$ depended on temperature, and were calculated following the procedure presented by de Diego et al. [14].

At that point, the oxygen-carrier-to-fuel ratio, $\phi$, and the solids inventory per thermal power in the fuel-reactor, $m_{F R}$, were introduced to better analyse the interrelation between fuel flow, pressure drop -i.e. the amount of solids in the reactors- and solids circulation flow rate [20]; see Table 2. $\phi$ was defined as the availability of oxygen in the flow of oxygen-carrier divided by the oxygen required to fully convert the fuel to $\mathrm{CO}_{2}$ and $\mathrm{H}_{2} \mathrm{O}$.

\subsection{Fluid dynamics and fuel conversion inside the fuel-reactor}

By way of example, the axial profile of solids concentration and gas velocity predicted in the fuelreactor for the test 10 are depicted in Fig. 4(a). The dense bed, characterized by a roughly constant porosity, was stretched out to a height of $0.4 \mathrm{~m}$. Above the dense bed, the solids concentration decreased with the reactor height. This finding agrees with results previously found in the DCFB [21]. Solids concentration subsequently increased at the entrance from the upper loop seal $(z=2$ $\mathrm{m})$.

Gas velocity increased through the reactor because of gas expansion during methane conversion. Abrupt changes in gas velocity were found at the position where steam entered from the internal and upper loop seals. Gas flow increased throughout the entire reactor; but a decrease in gas velocity was observed in the upper part of the reactor resulting from the core section increase above the saturation height. 
Submitted, accepted and published by

Proceedings of the Combustion Institute 37 (2019) 4361-4369

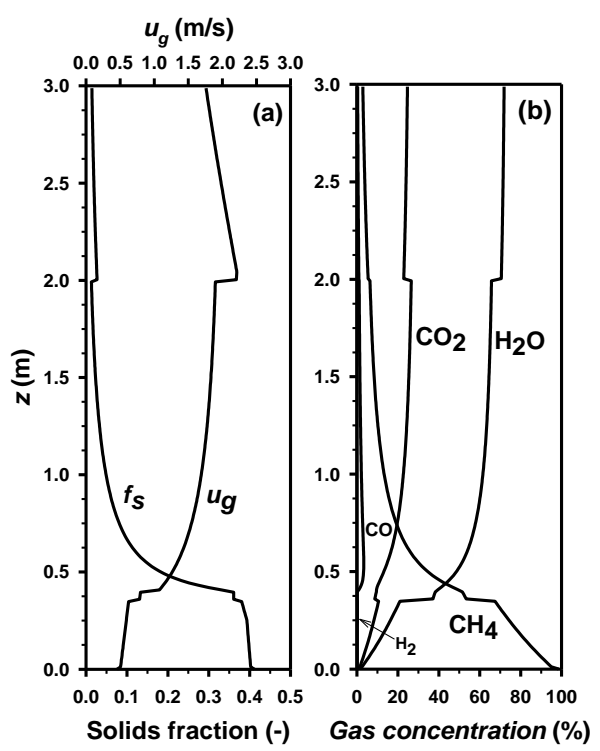

Fig. 4. Axial profiles in the fuel-reactor for test 10 of (a) solids fraction and gas velocity, and (b) gas concentration.

Fig. 4(b) shows the axial profiles of the concentration of gases. The methane inlet point corresponds to $z=0$, while the inlet of solids from the upper loop seal, which is fluidized by steam, is at $z=2 \mathrm{~m}$. In the dense bed, methane was slowly converted because the chemical reaction was restricted by the slower diffusion of methane from the bubbles to the emulsion phase, where reaction with the oxygen-carrier takes place. Methane conversion at the top of the dense bed was $X_{C_{4}}=14 \%$. Faster conversion had been predicted in the dilute region because the contact between gas and solids was improved in this region. Furthermore, a relevant improvement in methane conversion can be observed above $z=2 \mathrm{~m}$, caused by solids coming from the upper loop seal, which reached $X_{C_{4}}=91 \%$ at the reactor exit.

\subsection{Validation of the CLC model}

Fig. 5 compares the experimental and predicted values of methane conversion and combustion efficiency for the operating conditions shown in Table 2. In general, good agreement was found between the experimental and model predictions, with a deviation lower than $\pm 5 \%$ in most cases. 
Submitted, accepted and published by

Proceedings of the Combustion Institute 37 (2019) 4361-4369

Moreover, combustion efficiency values were close to those of methane combustion, indicating that the model also predicted very low $\mathrm{H}_{2}$ and $\mathrm{CO}$ concentration values, similar to those found during the tests [4]. Nevertheless, non-negligible deviations were found in some specific cases. These deviations are probably due to lack of reproducibility and associated uncertainty inherently associated to experimental data, as it will be discussed below.

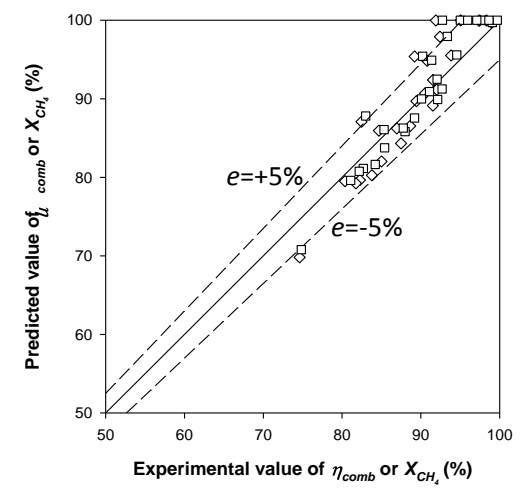

Fig. 5. Comparison between experimental and predicted values of methane conversion $(\square)$ and

$$
\text { combustion efficiency }(\diamond) \text {. }
$$

In test 16 , methane conversion was $95 \%$, whereas complete combustion had been predicted by the model. This test can be included together with tests 17 and 18 in an experimental series where solids inventory increased but the rest of operating conditions were maintained roughly constant; see Fig. 6(a). Methane conversion slightly increased with the solids inventory when tests 17 and 18 are considered. But, methane conversion in test 16 fell to $95 \%$, which is not a logical trend, probably due to the inherent uncertainty of experimental data. Of course, this illogical trend cannot be captured by the model.

This case is similar to that of test 24 , where the analysis can be performed with the effect of fuelreactor temperature; see Fig. 6(b). The tendency of methane conversion with temperature is perfectly demonstrated in series 24-12 and 20-4-21, where an increase in the temperature resulted in higher methane conversion. However, the importance of the temperature increase is higher in tests 24-12 than in tests 20-4-21. Theoretical results showed a similar trend for both series 24-12 
Submitted, accepted and published by

Proceedings of the Combustion Institute 37 (2019) 4361-4369

and 20-4-21, which resulted in a disagreement between the experimental methane conversion and the conversion predicted for test 24 .
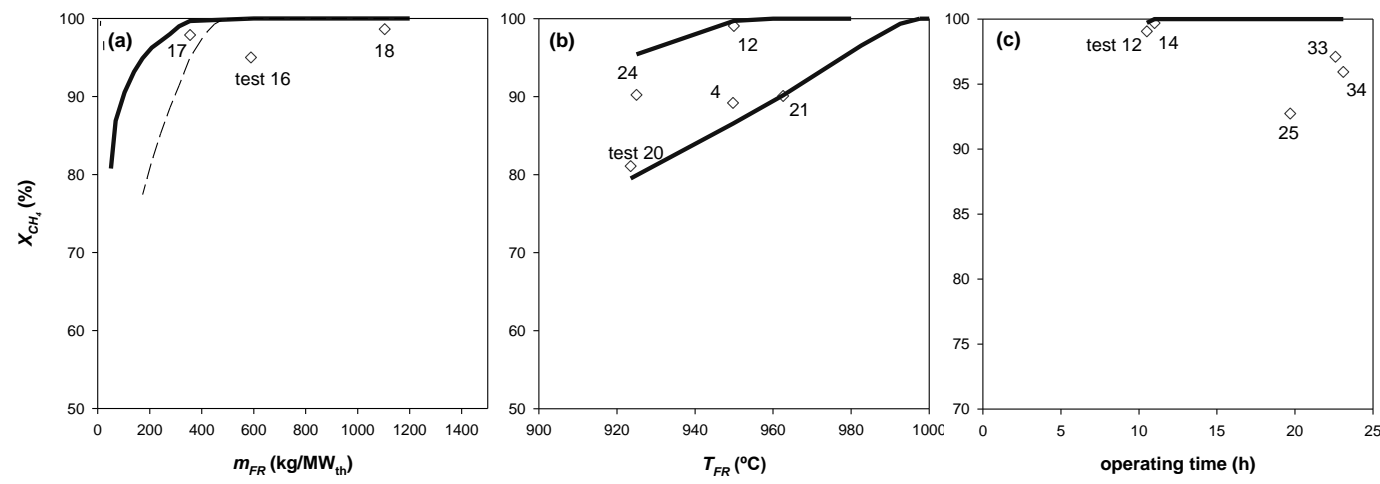

Fig. 6. Methane conversion in series varying: (a) solids inventory (tests 16-18); (b) temperature

(tests 20-4-21 and 24-12); (c) operating time (tests 12-14-25-28-29). Experimental ( $\diamond)$ and predicted ) values. Fig. (a) also shows the simulation with the inlet of solids in the dense

$$
\text { bed }(---) \text {. }
$$

Finally, methane conversion values for similar conditions (series 12-14-25-28-29) are plotted in Fig. 6(c). Obviously, the methane conversion predicted by the model is similar in all cases. However, the experimental methane conversion was lower for tests 25, 28 and 29. The difference could be found in a possible decrease in the oxygen uncoupling capacity of $\mathrm{CaMn}_{0.9} \mathrm{Mg}_{0.1} \mathrm{O}_{3-\delta}$ material with the operating time, as observed in a $500 \mathrm{~W}_{\text {th }}$ CLC unit [15].

Here, it is important to note that if the model had been modified for a better fit of results in tests 12, 24, 25, 28 and 29, agreement for the other tests would have been worse. Therefore, the model was considered to be validated, as good agreement between predicted and experimental values for methane conversion in the fuel-reactor was observed in most of the cases; see Fig. 5. This fact demonstrates that the fuel-reactor model adequately describes the processes taking place during the fuel conversion, as well as the effect of operating conditions on methane conversion. 
Submitted, accepted and published by

Proceedings of the Combustion Institute 37 (2019) 4361-4369

\section{Discussion}

The $\mathrm{CaMn}_{0.9} \mathrm{Mg}_{0.1} \mathrm{O}_{3-\delta}$ material is able to transfer oxygen to the fuel by gas-solid reaction and oxygen uncoupling mechanism, which is known as Chemical-Looping assisted by Oxygen Uncoupling (CLaOU) [22]. From results obtained with the CLC model it was possible to calculate the flow of oxygen being transferred inside the fuel-reactor via oxygen uncoupling by accounting for the oxygen reacted by reaction (R5) in the mass balances. As the total flow of oxygen transferred in the fuel-reactor was also known, the relative amount of oxygen transferred to the fuel via oxygen uncoupling could be calculated. Fig. 7(a) shows these values in regard to those of methane conversion. A clear relationship can be observed between the increase in the oxygen transferred via oxygen uncoupling and the increase in methane conversion. Moreover, the fraction of oxygen via oxygen uncoupling is more relevant at the lowest temperatures due to the low reactivity of the $\mathrm{CaMn}_{0.9} \mathrm{Mg}_{0.1} \mathrm{O}_{3-\delta}$ material with $\mathrm{CH}_{4}$ at these temperatures [14].
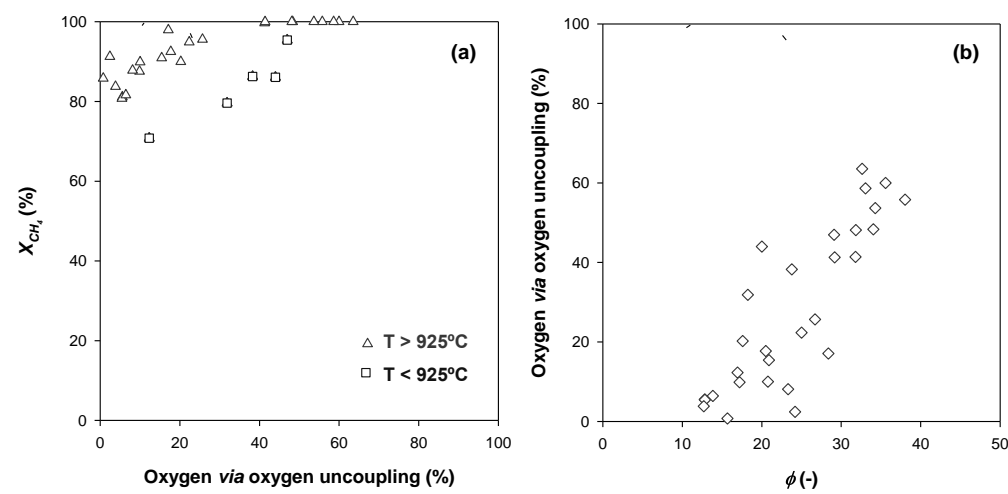

Fig. 7. Relevance to methane conversion of oxygen transferred to fuel via oxygen uncoupling.

It should be noted that the oxygen transport capacity for oxygen uncoupling, $R_{O C \text {,ou }}$, is lower than the total oxygen transport capacity, $R_{O C, t}$. Thus, very high solids circulation rates are necessary to increase the relevance of the oxygen uncoupling mechanism to oxygen transfer; see Fig. 7(b). Therefore, high temperature and oxygen-carrier-to-fuel ratio values are advisable in order to achieve complete fuel combustion in a CLC unit with the $\mathrm{CaMn}_{0.9} \mathrm{Mg}_{0.1} \mathrm{O}_{3-\delta}$ material. But the required temperature depends on other operating conditions. Fig. 6(b) shows that a temperature 
Submitted, accepted and published by

Proceedings of the Combustion Institute 37 (2019) 4361-4369

above $950{ }^{\circ} \mathrm{C}$ is required for high values of oxygen-carrier to fuel ratio $(\phi \approx 29)$ and solids inventory in the fuel-reactor $\left(m_{F R} \approx 340 \mathrm{~kg} / \mathrm{MW}\right)$. At these high $\phi$ values, the oxygen transference through the oxygen uncoupling mechanism is promoted, which clearly improves methane conversion; see Fig. 7 . But the required temperature is higher $\left(\approx 1000{ }^{\circ} \mathrm{C}\right)$ when lower values of $\phi$ $(\sim 17)$ and $m_{F R}(\sim 250 \mathrm{~kg} / \mathrm{MW})$ are used. In this case, most of oxygen is transferred via gas-solid reaction between methane and the oxygen-carrier. This reaction is relatively slow at temperatures below $1000{ }^{\circ} \mathrm{C}[14]$, which justify the high temperature required at lower $\phi$ values.

Considering conditions existing in tests $16-18$, i.e. $T_{F R} \approx 950{ }^{\circ} \mathrm{C}$ and $\phi \approx 34$, a minimum solids inventory to achieve complete methane conversion in the fuel-reactor of $m_{F R}=320 \mathrm{~kg} / \mathrm{MW}$ is deduced from results presented in Fig. 6(a).

In addition, it is also of interest to mention that the entry point for the solids in the fuel-reactor is highly relevant if good use is to be made of their oxygen uncoupling capability. Oxidized particles enter into the dilute region of the $\mathrm{DCFB}$, where a relatively low concentration of methane is to be found. To evaluate the relevance of the entry point of solids in the fuel-reactor, Fig. 6(a) shows predictions obtained assuming that solids enter in the dense bed, where they would be quickly mixed with existing solids in the reactor. In this case, methane conversion values are lower than those predicted when solids enter in the dilute region and a minimum solids inventory of $m_{F R}=$ $500 \mathrm{~kg} / \mathrm{MW}$ would be required to achieve complete methane combustion. Therefore, the oxygen uncoupling mechanism gains in relevance when solids enter in the dilute region, compared to the direct gas-solid reaction between the methane and the oxygen-carrier [23].

\section{Conclusions}

A theoretical model for Chemical-Looping Combustion (CLC) was developed for the combustion of methane with $\mathrm{CaMn}{ }_{0.9} \mathrm{Mg}_{0.1} \mathrm{O}_{3-\delta}$ material. This model properly predicted the fuel conversion in 29 tests conducted at the DCFB built at TUV. Thus, the effect of pressure drop, gas flow and 
Submitted, accepted and published by

Proceedings of the Combustion Institute 37 (2019) 4361-4369

temperature inside the fuel-reactor was properly described. In addition, it was determined that methane conversion could be highly improved by using an oxygen-carrier with oxygen uncoupling properties and that there was a window in operating conditions where this mechanism became prevalent. Therefore, the validated model is a powerful tool for simulating and optimizing the methane combustion in the fuel-reactor of a CLC system.

\section{Acknowledgments}

This work was supported by the seventh Framework Programme of the European Commission (INNOCUOUS Contract 241401), by the Spanish Ministry of Economy, Industry and Competitiveness (project ENE2016-77982-R), by the European Regional Development Fund (ERDF) and by the CSIC (project 2017-80E035). Authors thanks to K. Mayer and S. Penthor (TUV) for providing experimental data. 
Submitted, accepted and published by

Proceedings of the Combustion Institute 37 (2019) 4361-4369

\section{References}

[1] J. Adanez, A. Abad, F. García-Labiano, P. Gayán, L.F. de Diego, Prog. Energ. Combust. Sci. 38 (2012) 215-282.

[2] L.I. Eide, M. Anheden, A. Lyngfelt, C. Abanades, M. Younes, D. Clodic, Oil \& Gas Sci. Technol. 60 (2005) 497-508.

[3] A. Lyngfelt, B. Leckner, T. Mattisson, Chem. Eng. Sci. 56 (2001) 3101-3113.

[4] K. Mayer, S. Penthor, T. Pröll, H. Hofbauer, Applied En. 157 (2015) 323-329.

[5] M. Källén, M. Rydén, C. Dueso, T. Mattisson, A. Lyngfelt, Ind. Eng. Chem. Res. 52 (2013) 6923-6932.

[6] P. Hallberg, M. Hanning, M. Rydén, T. Mattisson, A. Lyngfelt, Int. J. Greenhouse Gas Control 53 (2016) 222-229.

[7] P. Ohlemüller, M. Reitz, J. Ströhle, B. Epple, Operation of a $1 \mathrm{MW}_{\text {th }}$ chemical looping pilot plant with natural gas, presented in the $7^{\text {th }}$ High Temperature Solid Looping Cycles Network Meeting, Luleå, Sweden, 2017.

[8] J. Adánez, A. Abad, T. Mendiara, P. Gayán, L.F. de Diego, F. García-Labiano, Prog. En. Comb. Sci. 65 (2018) 6-66.

[9] S.P. Sit, A. Reed, U. Hohenwarter, V. Horn, K. Marx, T. Proell, Energy Procedia 37 (2013) 671-676.

[10] A. Abad, P. Gayán, L.F. de Diego, F. García-Labiano, J. Adánez, Chem. Eng. Sci. 87 (2013) 277-293.

[11] A. Abad, P. Gayán, F. García-Labiano, L.F. de Diego, J. Adánez, Fuel Process. Technol. $171(2018) 78-88$.

[12] D. Pallerès, F. Johnsson, Prog. Energy Combust. Sci. 32 (2006) 539-569.

[13] O. Dewaele, G.F. Froment, Journal of Catalysis 184 (1999) 499-513.

[14] L.F. de Diego, A. Abad, A. Cabello, P. Gayán, F. García-Labiano, J. Adánez, Ind. Eng. Chem. Res. 53 (2014) 87-103. 
Submitted, accepted and published by

Proceedings of the Combustion Institute 37 (2019) 4361-4369

[15] A. Cabello, A. Abad, P. Gayán, L.F. de Diego, F. García-Labiano, J. Adánez, Energy Fuels 28 (2014) 1262-1274.

[16] W. Graven, J. Long, J. Am. Chem. Soc. 76 (1954) 2602-2608.

[17] F.L. Dryer, I. Glassman, presented at $14^{\text {th }}$ Symposium on combustion, Pennsylvania, 1973, p. $987-1003$.

[18] R.A. Srinivasan, S. Sriramulu, S. Kulasekaran, P.K. Agarwal, Fuel 77 (1998) 1033-1049.

[19] P. Kolbitsch, T. Proll, J. Bolhar-Nordenkampf, H. Hofbauer, Energy Fuels 23 (2009) 14501455.

[20] A. Abad, J. Adánez, F. García-Labiano, L.F. de Diego, P. Gayán, J. Celaya, Chem. Eng. Sci. 62 (2007) 533-549.

[21] T. Pröll, P. Kolbitsch, J. Bolhàr-Nordenkampf, H. Hofbauer, AIChE J. 55 (12) (2009) 32553266.

[22] R. Pérez-Vega, A. Abad, P. Gayán, L.F. de Diego, F. García-Labiano, J. Adánez, Fuel Process. Technol. 164 (2017) 69-79.

[23] D. Mei, A. Abad, H. Zhao, J. Adánez, Fuel Process. Technol. 133 (2015) 210-219. 
Submitted, accepted and published by

Proceedings of the Combustion Institute 37 (2019) 4361-4369

\section{Figure captions}

Fig. 1. Reactor scheme of the CLC process.

Fig. 2. Schematic diagram of the DCFB at TUV [4].

Fig. 3. Compilation of equations used in the fluid dynamic and mass balances sections of the model $[11,14]$.

Fig. 4. Axial profiles in the fuel-reactor for test 10 of (a) solids fraction and gas velocity, and (b) gas concentration.

Fig. 5. Comparison between experimental and predicted values of methane conversion $(\square)$ and combustion efficiency $(\diamond)$.

Fig. 6. Methane conversion in series varying: (a) solids inventory (tests 16-18); (b) temperature (tests 20-4-21 and 24-12); (c) operating time (tests 12-14-25-28-29). Experimental ( $\diamond)$ and predicted ) values.

Fig. 7. Relevance to methane conversion of oxygen transferred to fuel via oxygen uncoupling. 